\title{
Review Article \\ How Do Thermal Recovery Methods Affect Wettability Alteration?
}

\author{
Abhishek Punase, Amy Zou, and Riza Elputranto \\ Department of Petroleum Engineering, Texas A\&M University, College Station, TX 77840, USA \\ Correspondence should be addressed to Abhishek Punase; abhishekpunase@gmail.com
}

Received 10 June 2014; Revised 24 September 2014; Accepted 26 September 2014; Published 19 October 2014

Academic Editor: Guillaume Galliero

Copyright ( 2014 Abhishek Punase et al. This is an open access article distributed under the Creative Commons Attribution License, which permits unrestricted use, distribution, and reproduction in any medium, provided the original work is properly cited.

\begin{abstract}
We will investigate the effect of temperature on wettability. First, we will list and summarize the different schools of thoughts from previous literature describing wettability changes for sandstone and carbonate reservoirs at elevated temperature. Next, we will describe the properties that affect wettability: how they alter wettability and how they are affected by temperature. After that, we will present indications of wettability changes and current wettability measurement techniques. Following this, case studies describing how wettability change influences reservoir characteristics and field performance during thermal recovery processes will be discussed. The thermal recovery methods included in the case studies were steam flooding, cyclic steam injection, hot water flooding, and in situ combustion. The main and very important take away from this study is that temperature induced wettability change is determined by many possible mechanisms combined together and not by just one or two phenomena occurring simultaneously. Finally, we will propose a reasonable scheme for wettability alteration during dry forward combustion, which needs further investigation.
\end{abstract}

\section{Introduction}

Understanding formation rock wettability is very important for oil recovery optimization. Wettability is defined as the relative ability of a fluid to spread on a solid surface in the presence of other fluids [1]. The wettability of the fluid/rock system affects the distribution of fluids within a porous medium. The importance of wettability during recovery processes and enhanced oil recovery simulations has been stated previously in several literatures. For instance, a simulation study conducted by Salimi and Bruining [2] concluded that water-flooding results in low recovery in naturally fractured oil wet reservoirs as compared to water wet reservoirs. Certain wettability is favored in various reservoirs and production processes. Roosta et al. [3] stated that neutrally wet condition is favored over strongly oil wet in nonfractured reservoirs. However, not all reservoirs have the original wettability that favors production. The process of wettability alteration is therefore extremely relevant and applicable in these scenarios. Wettability is determined by a combination of many factors such as initial water saturation, saturation history, $\mathrm{pH}$, oil composition and asphaltenes deposition, clay content, and stability of the thin wetting water film on the rock surface [4]. All these properties do not remain constant during production and different recovery processes. In this paper, we will focus on how temperature elevation induced by thermal recovery methods alters some of these properties and therefore changes wettability. Temperature induced wettability alteration had been studied previously, and there were different opinions on how wettability changes in different types of reservoirs.

1.1. Temperature Induced Wettability Alteration in Sandstone Reservoirs. Many researchers have carried out experimental work on sandstone cores and studied its wettability with change in temperature. Edmondson [5] reported from his hot water experiment on Berea sandstone that temperature elevation resulted in decreasing relative permeability ratio and residual oil saturation, which indicated that the rock became more water-wet. 
Poston et al. [6] conducted a series of dynamic displacement relative permeability measurements on unconsolidated sands at high temperatures. In his study, he found that, for quartz, the residual water saturation and oil-water relative permeability increased and the residual oil saturation decreased with increasing temperature. The observation for unconsolidated sand also concurred with the previously published results as it became more water-wet at high temperature. He also reported that these changes are caused by the change in adhesion tension. Habowski [7] confirmed this observation in his experiment and showed that residual water increased and relative permeability ratio shifted with the increase in temperature. He even specified that the decrease in adhesion tension with increasing temperature is the reason which explains the change in relative permeability ratio.

More work was done by Sinnokrot [8] in which they calculated relative permeability curves from capillary pressure data at elevated temperatures and observed that sandstones became more water-wet as temperature increases. Residual oil saturation and relative permeability to water decreased, whereas irreducible water saturation and the relative permeability to oil increased with increasing temperature. In addition to these consistent results, they also added that hysteresis between drainage and imbibition gradually decreased as temperature is increased. Weinbrandt et al. [9] also carried out experiments with consolidated sands and obtained results similar to Sinnokrot. The shift in relative permeability curves towards higher water saturation with increase in temperature was attributed to the increase in water wetness behavior in the porous medium.

Contrary to the previously published results, some researchers like Wang and Gupta [10] had different observations. They found that the quartz surface became more oilwet as temperature increases. Karyampudi [11] also supported the findings of Wang and Gupta. A case study on similar lines was carried out by Blevins et al. [12]. It reviewed field results of steam flooding for heavy oil recovery and found out that the Northern Alberta sandstone reservoir became oil-wet due to steam injection. Recently, Escrochi et al. [13] stated that Berea sandstone became more oil-wet with temperature increase and restored to water-wet with further temperature increase.

These contrasting studies suggest that a comprehensive overview of wettability alteration should be carried out in order to understand its variation with temperature.

1.2. Temperature Induced Wettability Alteration in Carbonate Reservoirs. Carbonate reservoirs compared to sandstone reservoirs had very little disagreement between the researchers and most of them published similar observations. Hjelmeland and Larrondo [14] reported that calcite surface changed to water-wet and Lichaa et al. [15] also found similar results. Wang and Gupta [10] as well as Rao [16] published that carbonate became water-wet with temperature increase. Rao [16] confirmed in his study that calcium carbonate precipitation caused by temperature effect was the main reason for a sandstone reservoir not to be altered to oil wet at elevated temperature.

Furthermore, Blevins et al. [12] undertook a case-study and concluded from field data of Qarn Alam field in
Oman that carbonate reservoirs became more water-wet with increase in temperature. Also, Al-Hadhrami and Blunt [17] confirmed in their study that carbonate became more waterwet with temperature increment.

Therefore, in general, consensus is observed between the researchers that, with increase in temperature, the carbonate wettability changes to water-wet behavior.

1.3. Wettability Is Independent of Temperature. Another school of thought prevails that the increase in irreducible water saturation $\left(S_{\mathrm{wi}}\right)$ and decrease in residual oil saturation $\left(S_{\text {or }}\right)$ are independent of temperature and are caused due to the reduction in viscosity ratio.

This hypothesis was supported by the observations of Combarnous and Pavan [18], Hing and Lo Mungan [19], and Sufi et al. [20]. All the aforementioned studies point out that the shift in relative permeability curves is due to reduction in viscosity ratio. As per the case study undertaken by Sufi et al. [20] on the clean unconsolidated Ottawa sand, it was found that the decrease in "Practical" $S_{\text {or }}$ was due to the reduction in the viscosity ratio and the "Apparent" increase in $S_{\mathrm{wi}}$ was the result of a decrease in the viscous force provided by oil which, in turn, is caused by the viscosity reduction as temperature increases.

\section{Temperature Effects}

As mentioned in the introduction, wettability is determined by a combination of factors such as initial water saturation, saturation history, $\mathrm{pH}$, oil composition and asphaltenes deposition, clay content, and stability of the thin wetting water film on the rock surface [4]. If we want to understand how thermal recovery processes change wettability, we first need to answer the question: how does the elevated temperature caused by thermal processes affect each of the above properties individually?

2.1. Rock Composition and Clay Content. Since rocks have different composition, it is expected that they will have different properties, including original wettability. However, temperature elevation plays a role in altering these properties and thus the wettability needs to be investigated.

One of the main differences between sandstone and carbonates is their mineral composition. The main component in sandstone is quartz, which carries negative charge, whereas in carbonates, the main component which is calcium carbonate carries positive charge. In addition, it is determined by Cram [21] that the surface of quartz is weakly acidic and the surface of carbonate is weakly basic. The different charges and $\mathrm{pH}$ in sandstone and carbonate result in attraction of different polar components in crude oil and formation brine. For instance, sandstone will tend to attract basic components and the ones carrying positive charge. The different properties of the substance attached to the rock surfaces contribute in defining the wettability. However, experimental results have pointed out that the complex reacting forces between the chemical compounds in reservoir fluid and rock surface might not be simply due to basic attraction mechanisms. 
Denekas et al. [22] conducted an experiment with crude oil compounds at different acidities and clean cores. The oil fractions were allowed to age on the surface of the rock and results revealed that sandstone was affected by both acidic and basic compounds, whereas carbonates were mainly affected by the basic compounds. The differences in carbonate and sandstone composition and the compounds they attract from formation water lead to different wettability. Treiber et al. [23] concluded that carbonate rocks are more oil-wet than sandstone.

In addition to considering the existing rock properties, we also need to consider the effects of alteration of minerals at elevated temperature, as presented in the paper by $\mathrm{Ma}$ and Morrow [24]. During the firing experiment, they observed a permanent change in the structure of quartz, at temperature $573^{\circ}$ Celsius. There has not been a study conducted on the wettability change due to alteration of quartz crystal orientation; however, Potts and Kuehne [25] conducted firing of Berea sandstone cores and concluded that the core became strongly water-wet after firing. The largest alterations occur within the clay groups. For instance, kaolinite is transformed into smectite at high temperature [26]. Also in the paper by Shaw et al. [27], fine migration was observed during heating, which caused the clay particles to leave the surface of the rock, carrying oil with them and leaving the surface water wet.

2.2. Oil Composition. Certain components of crude oil, although present in relatively small amounts can affect the surface properties. For instance, Seifert and Howells [28] stated in their work that carboxylic acid acted like a surfactant at $\mathrm{pH}$ greater than 7 . The surface active compounds generally contain nitrogen, oxygen, and sulfur. These components are present in the polar fractions of crude oil, which are the heavy components: resin and asphaltenes. This statement is experimentally tested by Denekas et al. [22]. They verified the degree of wettability alteration caused by oil fractions using different molecular weight oil samples. The results indicated that the oil fraction with the heaviest components had the greatest impact on the rock sample and changed it to oil-wet, whereas the other oil fractions had no impact on the rock.

Experiment done by Johansen and Dunning [29] further supported the assumption and demonstrated that asphaltenes played a significant role in altering some of the systems towards oil-wet condition. They compared the resulting wettability of the same crude oil with and without asphaltenes. The results showed that the oil sample without asphaltenes had no impact on water-wet system, whereas the crude oil, which contains asphaltenes, altered the system towards oilwet system.

Akbarzadeh et al. [30] concluded that Athabasca bitumen asphaltenes precipitation decreased as the temperature was increased. An experimental study of asphaltenes precipitation versus temperature performed by Escrochi et al. [13] theoretically calculated that increase in temperature increases asphaltenes precipitation until the bubble point. With constant pressure, increasing temperature destabilizes the asphaltenes molecules in the crude oil and they form precipitation on the rock until the bubble point, where the difference in solubility parameters of asphaltenes and the mixture has its maximum value. Since asphaltenes are precipitating on the surface of the rock, the rock will behave more oil-wet at this temperature range. Above the bubble point pressure, more asphaltenes are in liquid phase. This means, for saturated and single phase reservoir, increase in temperature will increase asphaltenes solubility so that its precipitation decreases and the reservoir becomes water-wet.

From the above experimental studies, we concluded that the oil composition has significant impact on the system's wettability because crude oil components can act as surface activating agent. Also, the solubility of asphaltenes is a critical factor in determining the systems wettability.

2.3. Zeta Potential. As mentioned earlier, Anderson [4] stated that the clay on the surface of the rock absorbed polar compounds in the hydrocarbon such as asphaltenes and resin and made the surface oil-wet. Clay detachment, on the other hand, will reduce the amount of polar molecules on the rock surface, making the surface water-wet. Zeta potential can be used to calculate total potential between two particles in DLVO theory. If zeta potential becomes more negative, it means more repulsive force exists between the particles, whereas if the zeta potential is more positive, there is more attraction between the particles. In the work by Schembre et al. (1998) [31], they developed a function that describes the relationship between zeta potential and temperature for quartz/kaolinite and quartz/illite systems. They concluded, for both systems, that as the temperature increases, zeta potential becomes more negative, which indicates the force is repulsive and leads to clay detachment causing the rock to become more water-wet.

2.4. Solid Material Deposition. In the study conducted by Rao [32], he presented an experimental case involving two sides of the same quartz crystal. One side of the crystal was aged with oil and showed strongly oil-wet behavior at all temperatures. However when the other side of the crystal was examined with oil, it exhibited strongly water-wet behavior even after aging in oil and at elevated temperature. The question arose here was whether the properties of the second surface had been altered due to temperature elevation during the test on the first surface. Further inspection of the second surface revealed that the surface was covered with a layer of fine particles, which were identified as salts (mainly calcium carbonate and gypsum) contained in the brine used during the test. Literature review done by Rao [32] indicated that higher temperature results in decreasing solubility of calcium carbonate and causes precipitations. The solid precipitation was the cause of strongly water-wet behavior of the second surface of the quartz crystal. The effect of solid material deposition was later found to be one of the contributing factors that improved oil production rate and decreased water cut in the field [33].

Overall, high temperature will result in precipitation of some minerals that were originally in solution. In the case mentioned in this section, calcium carbonate precipitation caused the sandstone sample to become more water-wet. 


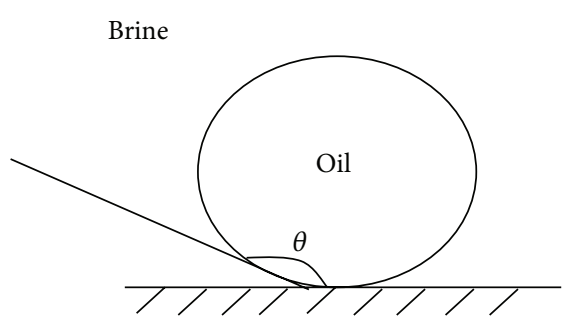

(a)

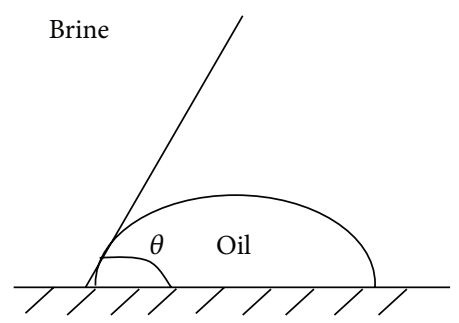

(b)

FIGURE 1: (a) Water-wet surface. (b) Oil-wet surface.

2.5. Stability of the Thin Wetting Water Film on the Rock Surface. The stability of the thin water film on the surface of the rock is governed by the brine's properties, such as electrolyte concentration and $\mathrm{pH}$. Derjaguin and Churaev [34] observed the effect of different temperature ranges on the stability of thin wetting water films on rock surface. Between 10 and $30^{\circ} \mathrm{C}$, the water film on silica decreased dramatically as the temperature increased. Between 30 and $50^{\circ} \mathrm{C}$, the decrease in water film thickness with an increase in temperature was not so obvious. And finally at temperature $50^{\circ} \mathrm{C}$ and above, they observed dramatic water film thickness reduction to almost monolayer of water molecule. They concluded as the temperature increases, the thickness of the wetting water film on silica decreases, which is caused by the breaking of hydrogen bonds. This result indicates that, at higher temperature, the rock surface shifts towards oil-wet tendency due to the thinning of water film.

2.6. $p H$. Generally speaking, the change of $\mathrm{pH}$ of a solution at different temperature can be neglected. However, since the wettability of a system partially depends on the $\mathrm{pH}$, we should investigate different mechanisms that describe $\mathrm{pH}$ change at elevated temperatures.

Firstly, as mentioned in solid material deposition section, carbonate scales were observed when the brine temperature increases. This precipitation of salt takes out the cations from solution, causing the $\mathrm{pH}$ to decrease.

Furthermore, Ramachandran and Somasundaran [35] described the dissolution of silica at high temperature using the following equations:

$$
\begin{aligned}
& \mathrm{SiO}_{2}+2 \mathrm{H}_{2} \mathrm{O}=\mathrm{H}_{4} \mathrm{SiO}_{4} \\
& \mathrm{H}_{4} \mathrm{SiO}_{4}=\mathrm{H}^{+}+\mathrm{H}_{3} \mathrm{SiO}_{4}{ }^{-}
\end{aligned}
$$

Therefore, we can say that as the temperature increases, the solution became more acidic due to the dissolved silica particles. Schembre and Kovscek (2004) stated in their study that as the $\mathrm{pH}$ decreases, zeta potential for kaolinite, illite, and quartz becomes more positive, which contributes to a more oil-wet surface.

2.7. Salinity. Salinity is a measurement of the amount of dissolved particles in a solution. In general, we can consider the changes in temperature to have small effects on brine salinity unless precipitation of the salts occurs. Chandrasekhar and
Mohanty [36] in their study concluded that lower salinity caused the rocks to become more water-wet, and they listed the following possible mechanisms behind wettability change from other literatures. First, decrease in salinity causes the amount of cations to decrease, which leads to slight increase in $\mathrm{pH}$. Higher $\mathrm{pH}$ may cause the generation of in situ calcium soap that will lower the interfacial tension. Secondly, bivalent ions with two bonds are replaced by monovalent ions and this process results in the detachment of the polar hydrocarbon surfactants (resin and asphaltenes), causing the rock surface to become more water-wet. And lastly, like mentioned earlier, decrease in the amount of bivalent and trivalent ions causes the zeta potential to become more negative, which means there is more repulsion between the clay particle and rock surface. The clay particle will be released at the threshold force that breaks the equilibrium and brings the hydrocarbon with them, leaving the surface more water-wet.

Overall, temperature increase will lead to lower brine salinity, which in turn results in more water-wet behavior of the rock surface.

\section{Indication of Temperature Induced Wettability Change}

Contact angle measurement is a very simple and accurate indication of the wettability. The most common method used in the laboratory for measuring contact angle is the sessile drop method [4]. The wettability of the surface is determined by measuring the angle formed between the solid surface and liquid at the surface as shown in Figure 1 (adapted from [37]). Figure 1(a) describes a water-wet surface, whereas Figure 1(b) illustrates an oil-wet surface.

As shown in Figure 1(b), oil tends to adhere to the rock surface in an oil-wet system. Oil molecule will attach and form a film on the surface of the pores and allows the center portion of the small pores to be occupied by water. During recovery processes such as water flooding, water will be channelled through these pores and will leave high residual oil saturation behind. The contact angle of an oil droplet on a surface is known to be affected by the surface tension between rock and the fluids as well as the interfacial tension between different fluid systems in contact with it.

Contact angle generally increases with increase in pressure, but this effect is not that predominant. Variation in temperature alters the contact angle of the fluid as well. This alteration is also dependent on the properties of the 
solid surface. For example, quartz is observed to be more water-wet compared to calcite at room temperature. Rao et al. [16] carried out contact angle measurements at different temperature conditions using single crystal contact angle and dual drop dual crystal techniques. The results from both the measurement methods indicated that quartz surface became more oil-wet, whereas calcium carbonate surface became water-wet with increase in temperature. This conclusion is contradicting to our existing knowledge of calcium carbonate being an oil-wet system. To understand this discrepancy, it is necessary to distinguish the two main aspects of wettability, namely, spreading and adhesion. In the work by Rao [16], receding contact angle corresponds to the spreading of the droplet of oil on surface, because spreading occurs when oil is displacing existing water causing it to recede. Similarly, the advancing contact angle is measured when water is advancing over a surface which oil was occupying. Normally, contact angle measurement is the measurement of the advancing angle since it closely resembles the nature of fluids flow in the reservoir as oil is produced. However, since these two mechanisms are regarded separately, oil spreading on a surface does not mean that the oil will adhere to the surface and vice versa. In this case, spreading of oil on calcium carbonate is not a direct indication that oil will adhere or form a film instead of water, because oil could spread on top of the water film without the water film being ruptured.

Another physical property indicative of the wettability variation with temperature is relative permeability. It is defined as a measure of the ability of the porous system to conduct one fluid when several fluids are present [38]. Since wettability determines the reservoir fluid's spatial distribution within the rock pores, relative permeability of a system is directly related to wettability. Relative permeability will aid in understanding if the oil phase is going to be easily and efficiently displaced during recovery processes. The viscous forces are temperature dependent and thus the relative permeability curve varies with temperature. For hightension system, the relative permeability of oil increases, whereas the relative permeability of water decreases with temperature increment at given saturation. These variations result in shifting of the curves to higher water saturation with increase in temperature, indicating a tendency of the rock to become more water-wet. For low-tension system, relative permeability of both water and oil increases with increase in temperature.

Recently conducted experiments by Rajayi and Kantzas [39] indicated that an increase in temperature will lead to lower interfacial tension (IFT) and larger contact angle of the bitumen/water interface. Therefore, the wettability of the system shifts from more water-wet to neutral wettability as temperature increases.

Many researchers observed that the relative permeability values dependent not only on the temperature and interfacial tension effect, but also on certain other physical properties.

Odeh and Cook [40] stated that the decrease in residual oil saturation with increase in temperature is caused by change in viscosity with temperature. Poston et al. (1970) [6] conducted a series of dynamic displacement relative permeability measurements on unconsolidated sands at elevated temperatures. Their results showed for clean quartz an increase in residual water saturation and oil-water relative permeability and a decrease in residual oil saturation with temperature increment. According to them, these changes are caused by the change in adhesion tension. The work of other researchers like Habowski [7], Sinnokrot (1969) [8], and Weinbrandt et al. [9] also concurred with results obtained by Poston et al.

\section{The Effects of Thermal Recovery Processes Induced Temperature Change on Wettability}

This following section will show some experiences in the fields which describe how wettability change influences reservoir characteristic and field performance during thermal recovery processes. The cases include hot water and steam injection in pilot project in Qarn Alam field, steam injection in Ghaba North field model, and cyclic steam stimulation (CSS) in pilot project in Elk Cumming Formation. We will also discuss how wettability change affects each zone during dry forward in situ combustion.

4.1. Hot Water and Steam Injection in Qarn Alam Field, Oman. Qarn Alam field is a fractured carbonate formation in Shuaiba/Kharaib/Lekhwair reservoir, Oman. The field contains 213 million $\mathrm{m}^{3}$ of heavy oil. The oil density is around 16 API, and the oil viscosity is approximately $220 \mathrm{cp}$ at reservoir condition. Most of the heavy oil is found in the Gharif, Al Khlata, and Haima formation at depth 900-1300 m. The reservoir is oil-wet system with extensive amount of high permeability fractures and low matrix permeability.

The production began in 1975 with the ultimate recovery efficiency under gas lift mechanism only achieving about $2 \%$ of stock tank oil initially in place (STOIIP). The other problem is the water cut went up to $95 \%$ within two years of production because the reservoir has a strong aquifer support. This problem also increased the water level and left a $40 \mathrm{~m}$ of oil rim within the fracture.

Blevins et al. [12] reviewed field studies of steam flooding for heavy oil recovery and found that the Northern Alberta sandstone reservoir became oil-wet due to steam injection and Qarn Alam carbonate reservoir become more waterwet. Based on Al-Adawy and Nandyal [41], Macaulay et al. [42], and Al-Shizawi et al. [43], Qarn Alam field was tested for some thermal recovery projects including hot water and steam injection.

Hot water injection was favored to be the first pilot project in 1985 because this method was expected to enhance the oil recovery by reducing oil viscosity and changing the oilwet system into water-wet system. During the pilot, hot water was injected at rate $500 \mathrm{~m}^{3} / \mathrm{d}$. The bottom-hole temperature increased to $195^{\circ} \mathrm{C}$. The residual oil saturation decreased from $88 \%$ to $46 \%$ across the perforated intervals after hot water flood, which represent significant improvement in oil recovery. However, the test did not observe saturation changes at elevated temperature in the interval above the 
perforations which made the test results inconclusive and investigation had to be stopped in 1987.

In the study conducted by Tang et al. [44], it was observed that the factor that has the most influence on the oil recovery at elevated temperature in the carbonate reservoir is dominated by imbibition. When temperature increases from 100 to $400^{\circ} \mathrm{F}$, the steam injection changes the carbonate reservoir from neutral to strongly water-wet condition, which improves oil recovery by free imbibition. The study by Tang et al. in 2012 [45] also proved that this imbibition potential at high temperature is due to mineral dissolution.

The other proposed method to improve oil recovery in Qarn Alam is Steam Assisted Gas-Oil Gravity Drainage. The pilot project was initiated in 1996. It was forced to a stop in 1997 due to steam-injection plant problem but it was resumed in 1998. The reservoir was heated by steam, and the temperature increased from $50^{\circ} \mathrm{C}$ to $240^{\circ} \mathrm{C}$ after 5 -month injection.

Laboratory results indicated that, at $50^{\circ} \mathrm{C}$, the core was still in oil-wet system which makes the core hard to imbibe with water. After $240^{\circ} \mathrm{C}$, the heating induced by steam reduced the oil viscosity to $2 \mathrm{cp}$. The temperature change also reduced the acid number on carbonate and made the rock water-wet. Therefore, the core imbibes significant amount of water and the gravity drainage rate was improved at elevated temperature. Rao [16] supported this result in his paper stating that carbonate rock becomes water-wet when temperature increases. Steam flood in this field increased total recovery by $11 \%$.

4.2. Steam Flooding in Model of Ghaba North Field in Oman. Ghaba North field is carbonate reservoir, with the original wettability being strongly oil-wet. The original oil in place (OOIP) is 119 million $\mathrm{m}^{3}$. The oil density is around $27 \mathrm{API}$, and oil viscosity is approximately $7 \mathrm{cp}$. Ghaba North field is a fracture reservoir with $30 \%$ average porosity, $10 \mathrm{md}$ matrix permeability, $100 \mathrm{md}$ fracture permeability, and 5$10 \mathrm{~m}$ fracture spacing. The fracture spacing of Ghaba North is wider than Qarn Alam. This wide fracture spacing also makes the time scale for heat transport into matrix more significant. Between 1990 and 1995, the field was produced under gas lift, but only $2 \%$ recovery was achieved.

Al-Hadhrami and Blunt [17] studied this field and stated that water must overcome a capillary barrier, which was estimated to be $80 \mathrm{KPa}$ to invade the rock matrix and displace the oil in oil-wet rock. Therefore, reducing the capillary barrier by lowering interfacial tension or altering the rock wettability was needed to achieve higher recovery. The change of oil-wet rock to water-wet rock will allow water imbibition into the rock matrix. Therefore, in Ghaba North field, the goal of steam injection is to induce wettability change of the reservoir instead of viscosity reduction.

Roosta et al. discovered in 2009 [3] that steam could reverse the wettability alteration in calcite and quartz surface into water-wet condition by washing out the precipitated asphaltenes molecules from the surface. Das [46] stated the parameters that alter the most in thermal recovery are wettability and capillary pressure.
The clean carbonate rock surface is water-wet initially. When the oil invades the pore, the capillary pressure is exceeded and the water film ruptures. It makes the oil contact the surface directly and the system becomes oil-wet. The temperature elevation by steam injection can change most carbonate reservoir to be more water-wet and increase recovery Morrow et al. (1998) [47]. The steam will heat the rock matrix to induce a wettability change. Then, hot water can spontaneously flow into the matrix and displace oil.

Al-Hadhrami and Blunt [17] developed a 1-dimensional model to analyze the use of thermally induced wettability transition to improve oil recovery in fracture reservoir. From their observation, imbibition will occur over matrix face and create counter current flow. During the steam injection, the imbibition rate is limited by capillary force if the heat is transporting fast. The time for recovery was adjusted with scaling using Ghaba North properties and $30 \%$ of recoverable oil is displaced for 20-80 days for counter current imbibition into a matrix block, which indicates the imbibition does not control recovery alone. With advance analysis, the time taken to displace the steam into the matrix with a distance height around $2.5-5 \mathrm{~m}$ is estimated between 180 and 740 days. The application in Ghaba North field showed that $30 \%$ of oil recovery is displaced in a single matrix block after 700 days of steam injection.

4.3. Cyclic Steam Injection. Olsen (1991) [48] stated that wettability shifts towards water-wet behavior as the system temperature increases. He also found that oil saturation decreases during steam flooding. With some of the mechanisms of wettability change stated above, wettability change during cyclic steam stimulation (CSS) has been studied, and the results are debatable. Most scholars believe both sandstone and carbonate will alter to more water wet during CSS process. Hascakir and Kovscek [49] report that the water-oil relative permeability curve shifts to the right at high temperature, which makes the oil production increases drastically in CSS. Schembre et al. (2004) stated wettability change is associated with fine mobilization in the diatomite cores and only occurs at or above a specific temperature. Other cases were also studied by different scholars and results were proven to be similar.

The wettability impact on CSI also has been reported by Karyampudi (1995) [11] through Elk Point heavy oil project. This project was located in Cumming formation of Alberta Field. The field is mainly heavy oil and bitumen. The oil density is 13 API and oil viscosity is $10000 \mathrm{cp}$ at reservoir temperature of $24^{\circ} \mathrm{C}$. The primary oil production was $8.5 \mathrm{~m}^{3} / \mathrm{d}$ with water cut up to $35 \%$. The original oil in place (OOIP) of the section was 7.6 million $\mathrm{m}^{3}$ with the ultimate recovery under primary production $15 \%$ OOIP. The main problem of Elk Point was high oil viscosity, poor reservoir quality, and high water saturation.

The CSS pilot was started in 1983. By the end of 1995, there were a total of 27 experimental CSSs. The first four cycles resulted in decrease in oil production and increase in water cuts. The injection and production data analysis showed the wettability of formation around the wellbore reservoir shifted 


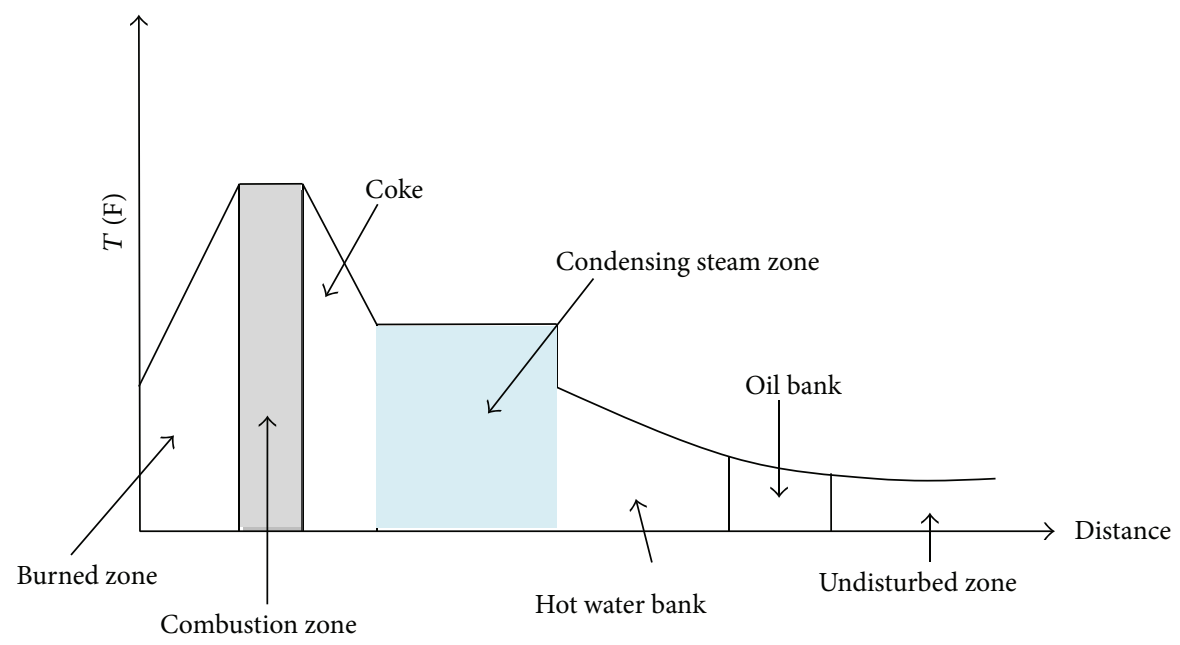

FIGURE 2: In situ combustion temperature profile for different zones (adapted from [50]).

to oil-wet behavior at elevated temperature. The laboratory investigation in 1988 also confirmed this result. Rao and Karyampudi [33] concluded that wettability shifted to oilwet behavior and reduction in oil relative permeability during CSS was one of the factors responsible for poor performance in one formation. The formation is composed of $87 \%$ sand, and at the testing temperature $\left(162-196^{\circ} \mathrm{C}\right)$, the sand became oil-wet due to the rupture of wetting film. However, in their paper, they discussed the effect of calcium carbonate deposition due to decreasing solubility at high temperature on wettability and concluded that it prevented the sandstone from changing to more oil wet at high temperature. In addition to the laboratory results, field testing also supported the statement.

Based on Rao and Karyampudi report [33], the wettability control technique using in situ calcium carbonate deposition was implemented in the fifth cycle on 1990. It involved injecting some amount of sodium bicarbonate dissolved in softened water into the steam pipe at the steam generator discharge and some amount of calcium chloride dissolved in hot softened water into the formation in the middle of steam injection. The result was a slight increase in oil rate and a decrease in $S_{\text {or }}$. However, this technique also triggered an inadvertent fracture event that increases the water cut over to $90 \%$.

From Elk Point thermal pilot performance, Miller and Ramey Jr. (1985) [51] recommended a set of screening guidelines for CSS. The reservoir which is considered for CSS should have oil rates under primary production between 2 and $6 \mathrm{~m}^{3} / \mathrm{d}$ and water cut under primary production should be lower than $15 \%$.

4.4. In Situ Combustion. There was no previous field case that describes the effect of wettability change due to in situ combustion. However, we will have a discussion on the wettability change effect in each zone during in situ combustion process. As shown in Figure 2, there are several zones with different temperatures during in situ combustion process.
Technically, temperature can affect relative permeability by changing the wettability or reducing the interfacial tension (IFT) between water and oil. Bardon and Longeron [52] and Haniff and Ali [53] reported that the relative permeability change significantly at IFT below $0.1 \mathrm{dyne} / \mathrm{cm}^{2}$. This condition should be observed in the burned zone, combustion zone, and coke zone since all three zones have very high temperature. Therefore, IFT between water and oil can decrease and change the relative permeability for in situ combustion process. On the other hand, the relative permeability will continue to decrease until it approaches zero saturation.

The high temperature also produces water in the gas phase which condenses when reaching a cooler zone and becomes water bank. Butler [54], Castanier and Brigham [55], and Sarathi [50] reported that the steam and water bank that are formed during in situ combustion will influence oil production and act as a hot water injection. In these zones, irreducible water saturation increases and the residual oil saturation decreases smoothly.

The heating effect from coke burning has not reached the undisturbed zone. Therefore, the change of temperature in undisturbed zone is insignificant. The relative permeability curve for this zone will remain similar to the original relative permeability curve.

\section{Conclusions}

(1) Understanding wettability is very important during oil recovery.

(2) Wettability is determined by a combination of factors.

(3) There are discrepancies on how temperature affects rock wettability. The following are possible reasons behind the different thoughts.

(a) Some scholars interpret wettability solely based on relative permeability, but wettability is not the only reason to cause relative permeability to shift. 
(b) There is no consistent measurement on wettability. Researchers have been using different methods (Amott test, contact angle measurement, analyzing relative permeability curves, etc.) to evaluate wettability, which causes inconsistency when comparing results.

(c) One has to take into consideration all the factors that affect wettability and not just one or two phenomena occurring separately.

(4) Clay contents (the amount of each clay type presented in rock) and the degree of clay alteration at elevated temperature need further investigation.

(5) The wettability alteration mechanism during different EOR techniques, especially in situ combustion, needs more research.

\section{Conflict of Interests}

The authors declare that there is no conflict of interests regarding the publication of this paper.

\section{Acknowledgments}

The authors would like to extend their heartfelt gratitude to Dr. Berna Hascakir for her constant motivation and guidance throughout the course of this paper. They also acknowledge the suggestions from all our friends and colleagues towards the betterment of this paper.

\section{References}

[1] A. G. Mitchell, L. B. Hazell, and K. J. Webb, "Wettability determination: pore surface analysis," in Proceedings of the SPE Annual Technical Conference and Exhibition, New Orleans, La, USA, September 1990.

[2] H. Salimi and J. Bruining, "The influence of wettability on oil recovery from naturally fractured oil reservoirs including nonequilibrium effects," in Proceedings of the SPE Latin American and Caribbean Petroleum Engineering Conference, SPE-138366MS, Lima, Peru, December 2010.

[3] A. B. Roosta, M. F. Escrochi, V. J. Khatibi, V. J. S. Ayatollahi, and M. Schafiee, "Investigating the mechanism of thermally induced wettability alteration," in SPE Middle East Oil and Gas Show and Conference, Bahrain, Bahrain, March 2009.

[4] W. G. Anderson, "Wettability literature survey-part 1: rock/oil/brine interactions and the effects of core handling on wettability," Journal of Petroleum Technology, vol. 38, no. 10, Article ID SPE-13932-PA, pp. 1125-1144, 1986.

[5] T. A. Edmondson, "Effect of temperature on waterflooding," Journal of Canadian Petroleum Technology, vol. 4, no. 4, Article ID PETSOC-65-04-09, pp. 236-242, 1965.

[6] S. W. Poston, S. Ysreal, A. K. M. S. Hossain, E. F. Montgomery III, and H. J. Ramey Jr., "The effect of temperature on irreducible water saturation and relative permeability of unconsolidated sands," Society of Petroleum Engineers Journal, vol. 10, no. 2, pp. 171-180, 1970.

[7] E. Habowski, The effect of large temperature changes on relative permeability ratio [M.S. thesis], The Pennsylvania State University, Pennsylvania, Pa, USA, 1966.
[8] A. A. Sinnokrot, The effect of temperature on capillary pressure curves of limestone and sandstones [Ph.D. dissertation], Stanford University, 1969.

[9] R. M. Weinbrandt, H. J. Ramey Jr., and F. J. Casse, "The effect of temperature on relative and absolute permeability of sandstones," Society of Petroleum Engineers Journal, vol. 15, no. 5, pp. 376-384, 1975.

[10] W. Wang and A. Gupta, "Investigation of the effect of temperature and pressure on wettability using modified pendant drop method," in Proceedings of the SPE Annual Technical Conference and Exhibition, SPE 30544, Dallas, Tex, USA, October 1995.

[11] R. S. Karyampudi, "Evaluation of cyclic steam performance and mechanisms in a mobile heavy oil reservoir at Elk Point thermal pilot," Journal of Canadian Petroleum Technology, vol. 34, no. 3, pp. 48-56, 1995.

[12] T. R. Blevins, J. H. Duerksen, and J. W. Ault, "Light-oil steam flooding - an emerging technology," Journal of Petroleum Technology, vol. 36, no. 8, pp. 1115-1122, 1984.

[13] M. Escrochi, M. Nabipour, S. S. Ayatollahi, and N. Mehranbod, "Wettability alteration at elevated temperatures: the consequenses of asphaltene precipitation," in Proceedings of the SPE International Symposium and Exhibition on Formation Damage Control, Lafayette, La, USA, February 2008.

[14] O. S. Hjelmeland and L. E. Larrondo, "Experimental investigation of the effects of temperature, pressure, and crude oil composition on interfacial properties," SPE Reservoir Engineering, vol. 1, no. 4, Article ID SPE-12124-PA, pp. 321-328, 1986.

[15] P. M. Lichaa, H. Alpuston, J. H. Abdul, W. A. Nofal, and B. F. AlHasan, "Wettability evaluation of a carbonate reservoir rock," in Proceedings of the European Core Analysis Symposium, Paris, France, September 1992.

[16] D. N. Rao, "Wettability effects in thermal recovery operations," SPE Reservoir Evaluation \& Engineering, vol. 2, no. 5, pp. 420430, 1999.

[17] H. S. Al-Hadhrami and M. J. Blunt, "Thermally induced wettability alteration to improve oil recovery in fractured reservoirs," in Proceedings of the SPE/DOE Improved Oil Recovery Symposium, SPE 71866, Tulsa, Okla, USA, April 2001.

[18] M. Combarnous and J. Pavan, "Deplacement par l'eau chaude d'huilesen place dans un milieu poreux," in Me Colloque de I'ARTFP, paper 37, pp. 737-757, Pau, France, September 1968, (French).

[19] Y. Hing and N. Lo Mungan, "Effect of temperature on wateroil relative permeabilties in oil-wet and water-wet systems," SPE 4505, 1973.

[20] A. H. Sufi, J. H. Ramey Jr., and W. E. Brigham, “Temperature effects on relative permeabilities of oil-water systems," in SPE Annual Technical Conference and Exhibition, New Orleans, Lo, USA, September 1982.

[21] P. J. Cram, "Wettability studies with non-hydrocarbon constituents of crude oil," Research Report RR-17, Petroleum Recovery Research Inst., 1972.

[22] M. O. Denekas, C. C. Mattax, and G. T. Davis, "Effect of crude oil components on rock wettability," American Institute of Mining, Metallurgical, \& Petroleum Engineers, vol. 216, pp. 330-333, 1959.

[23] L. E. Treiber, D. L. Archer, and W. W. Owens, "A laboratory evaluation of wettability of fifty oil producing reservoirs," Society of Petroleum Engineers Journal, vol. 12, no. 6, pp. 531540, 1972.

[24] S. Ma and N. R. Morrow, "Effect of firing on petrophysical properties of Berea sandstone," SPE Formation Evaluation, vol. 9, no. 3, pp. 213-218, 1994. 
[25] D. E. Potts and D. L. Kuehne, "Strategy for alkaline/polymer flood design with berea and reservoir-rock corefloods," SPE Reservoir Engineering, vol. 3, no. 4, pp. 1143-1152, 1988.

[26] D. A. Bennion, F. B. Thomas, and D. A. Sheppard, "Formation damage due to mineral alteration and wettability changes during hot water and steam injection in clay-bearing sandstone reservoirs," in Proceedings of the SPE Formation Damage Control Symposium, SPE 23783, Lafayette, La, USA, February 1992.

[27] J. C. Shaw, P. L. Churcher, and B. F. Hawkins, "Effect of firing on Berea sandstone," SPE Formation Evaluation, vol. 6, no. 1, pp. 72-78, 1991.

[28] W. K. Seifert and W. G. Howells, "Interfacially active acids in a California crude oil. Isolation of carboxylic acids and phenols," Analytical Chemistry, vol. 41, no. 4, pp. 554-562, 1969.

[29] R. T. Johansen and H. N. Dunning, "Relative wetting tendencies of crude oils by capillarimetric method," USBM Report RI 5752, 1961.

[30] K. Akbarzadeh, O. Sabbagh, J. Beck, W. Y. Svrcek, and H. W. Yarranton, "Asphaltene precipitation from bitumen diluted with n-alkanes," in Proceedings of the Canadian International Petroleum Conference, PETSOC-2004-026-EA, Petroleum Society of Canada, Alberta, Canada, June 2004.

[31] M. Schembre, R. Kovscek, and G. Q. Tang, "Effect of temperature on relative permeability for heavy-oil diatomite reservoirs," in Proceedings of the SPE Western Regional Meeting, SPE 93831, Irvine, Calif, USA, March-April 2005.

[32] D. N. Rao, "Wettability effects in thermal recovery operations," SPE Reservoir Evaluation \& Engineering, vol. 2, no. 5, pp. 420430, 1996.

[33] D. N. Rao and R. S. Karyampudi, "Productivity enhancing wettability control technology for cyclic steam process in the Elk Point Cummings formation," Journal of Canadian Petroleum Technology, vol. 38, no. 13, 1999.

[34] B. V. Derjaguin and N. V. Churaev, "On the question of determining the concept of disjoining pressure and its role in the equilibrium and flow of thin films," Journal of Colloid and Interface Science, vol. 66, no. 3, pp. 389-398, 1978.

[35] R. Ramachandran and P. Somasundaran, "Effect of temperature on the interfacial properties of silicates," Colloids and Surfaces, vol. 21, pp. 355-369, 1986.

[36] S. Chandrasekhar and K. K. Mohanty, "Wettability alteration with brine composition in high temperature carbonate reservoirs," in SPE Annual Technical Conference and Exhibition, vol. 166280 of Proceedings of SPIE, pp. 2416-2432, October 2013.

[37] Y. H. Yuan and R. T. Lee, Surface Science Techniques, Springer, Berlin, Germany, 2013.

[38] W. G. Anderson, "Wettability literature survey part 5: the effects of wettability on relative permeability," Journal of Petroleum Technology, vol. 39, no. 11, Article ID SPE-16323-PA, pp. 14531468, 1987.

[39] M. Rajayi and A. Kantzas, "Effect of temperature and pressure on contact angle and interfacial tension of quartz/water/bitumen system," Journal of Canadian Petroleum Technology, vol. 50, no. 6, Article ID SPE-148631-PA, pp. 61-67, 2009.

[40] A. S. Odeh and E. L. Cook, "Discussion-effect of temperature on waterflooding," Journal of Canadian Petroleum Technology, vol. 4, no. 4, p. 242, 1965.

[41] M. S. Al-Adawy and M. Nandyal, "Status and scope for EOR development in Oman," in Middle East Oil Show, Society of Petroleum Engineers, November 1991, SPE 21407.
[42] R. C. Macaulay, J. M. Krafft, M. Hartemink, and B. Escovedo, "Design of a steam pilot in a fractured carbonates reservoirQarn Alam field," in Proceedings of the SPE International Heavy Oil Symposium, vol. 30300 of SPE 30300, Alberta, Canada, June 1995.

[43] A. Al-Shizawi, P. G. Denby, and G. Marsden, "Heat-front monitoring in the Qarn Alam thermal GOGD pilot," in Proceedings of the Middle East Oil Show and Conference, SPE 37781, Society of Petroleum Engineers, March 1997.

[44] G. Q. Tang, A. Inouye, D. Lowry, and V. Lee, "Recovery mechanism of steam injection in heavy oil carbonate reservoir," in Proceedings of the SPE Western North American Region Meeting, Anchorage, Alaska, USA, May 2011.

[45] G.-Q. Tang, A. Inouye, V. Lee, D. Lowry, and W. Wei, "Investigation of recovery mechanism of steam injection in heavy oil carbonate reservoir and mineral dissolution," in Proceedings of the Society of Petroleum Engineers Western Regional Meeting, vol. 153812 of SPE, pp. 457-471, March 2012.

[46] S. Das, "Application of thermal recovery processes in heavy oil carbonate reservoirs," in Proceedings of the 15th SPE Middle East Oil and Gas Show and Conference, 2007, SPE 105392.

[47] N. R. Morrow, G.-Q. Tang, M. Valat, and X. Xie, "Prospects of improved oil recovery related to wettability and brine composition," Journal of Petroleum Science and Engineering, vol. 20, no. 3-4, pp. 267-276, 1998.

[48] D. K. Olsen, "Effect of wettability on light oil steam flooding," Topical Report NIPER-552, USDOE, 1991.

[49] B. Hascakir and A. R. Kovscek, "Reservoir simulation of cyclic steam injection including the effects of temperature induced wettability alteration," in Proceedings of the SPE Western Regional Meeting, SPE 132608, Anaheim, Calif, USA, May 2010.

[50] P. S. Sarathi, "In-situ combustion handbook-principles and practices," Tech. Rep. DOE/PC/91008-0374, National Petroleum Technology Office, U.S. Department of Energy, Tulsa, Okla, USA, 1999.

[51] M. A. Miller and H. J. Ramey Jr., "Effect of temperature on oil/water relative permeabilities of unconsolidated and consolidated sands," Society of Petroleum Engineers Journal, vol. 25, no. 6, pp. 945-953, 1985.

[52] C. Bardon and D. G. Longeron, "Influence of very low interfacial tensions on relative permeability," Society of Petroleum Engineers Journal, vol. 20, no. 5, pp. 391-401, 1980.

[53] M. S. Haniff and J. K. Ali, "Relative permeability and low tension fluid flow in gas condensate systems," in Proceedings of the European Petroleum Conference, SPE-20917-MS, The Hague, Netherlands, October 1990.

[54] R. M. Butler, Thermal Recovery of Oil and Bitumen, Prentice Hall, 1991.

[55] L. M. Castanier and W. E. Brigham, "Upgrading of crude oil via in situ combustion," Journal of Petroleum Science and Engineering, vol. 39, no. 1-2, pp. 125-136, 2003. 

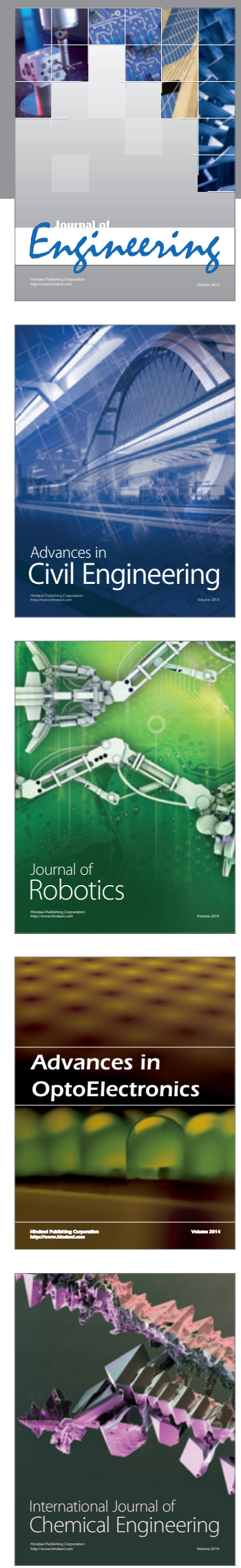

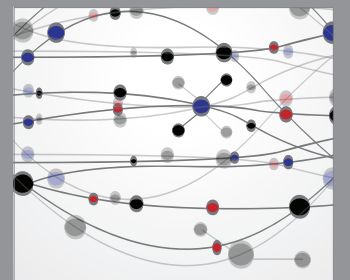

The Scientific World Journal
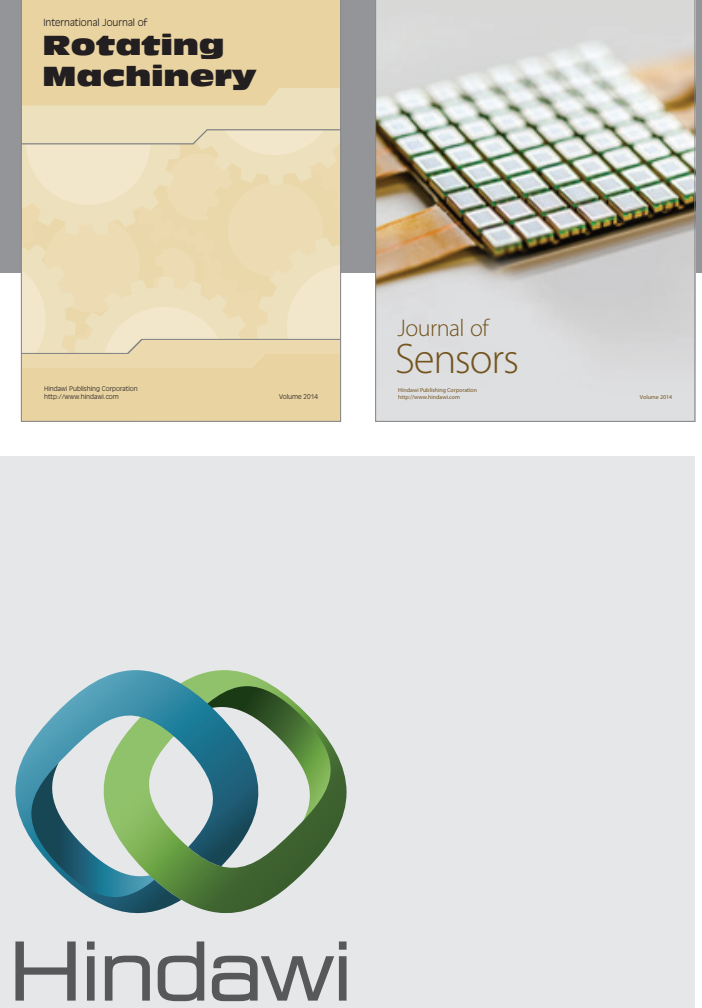

Submit your manuscripts at http://www.hindawi.com
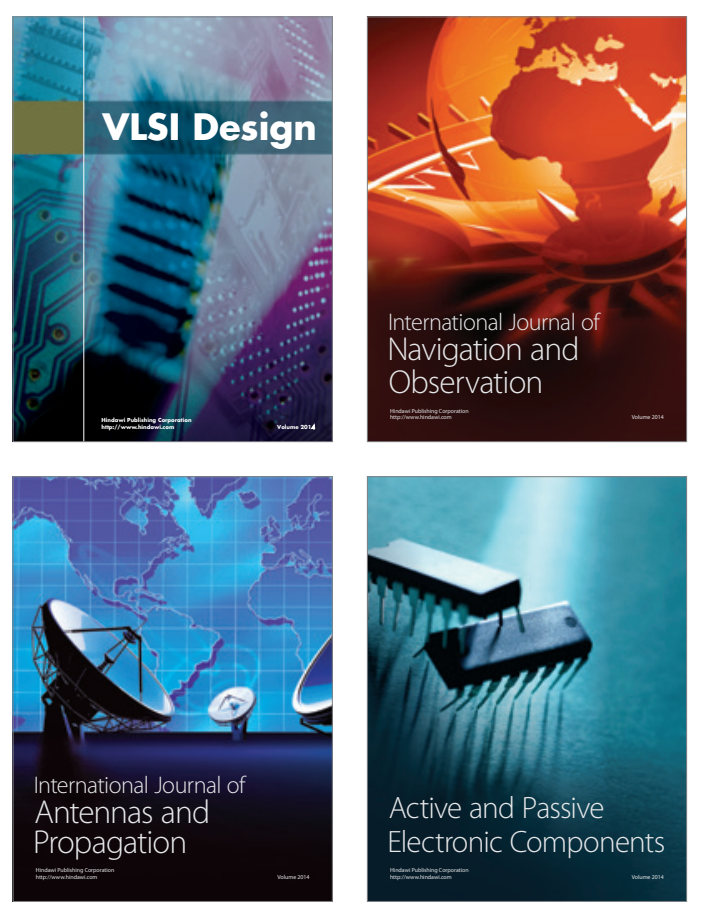
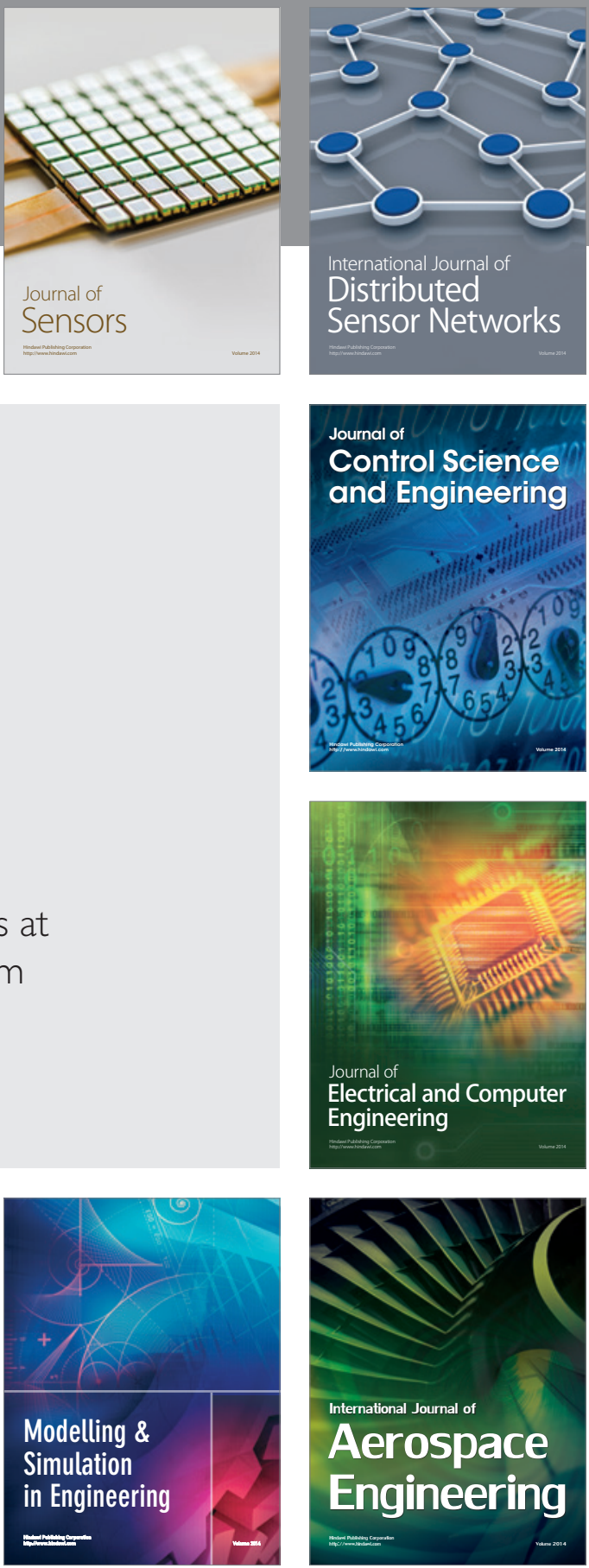

Journal of

Control Science

and Engineering
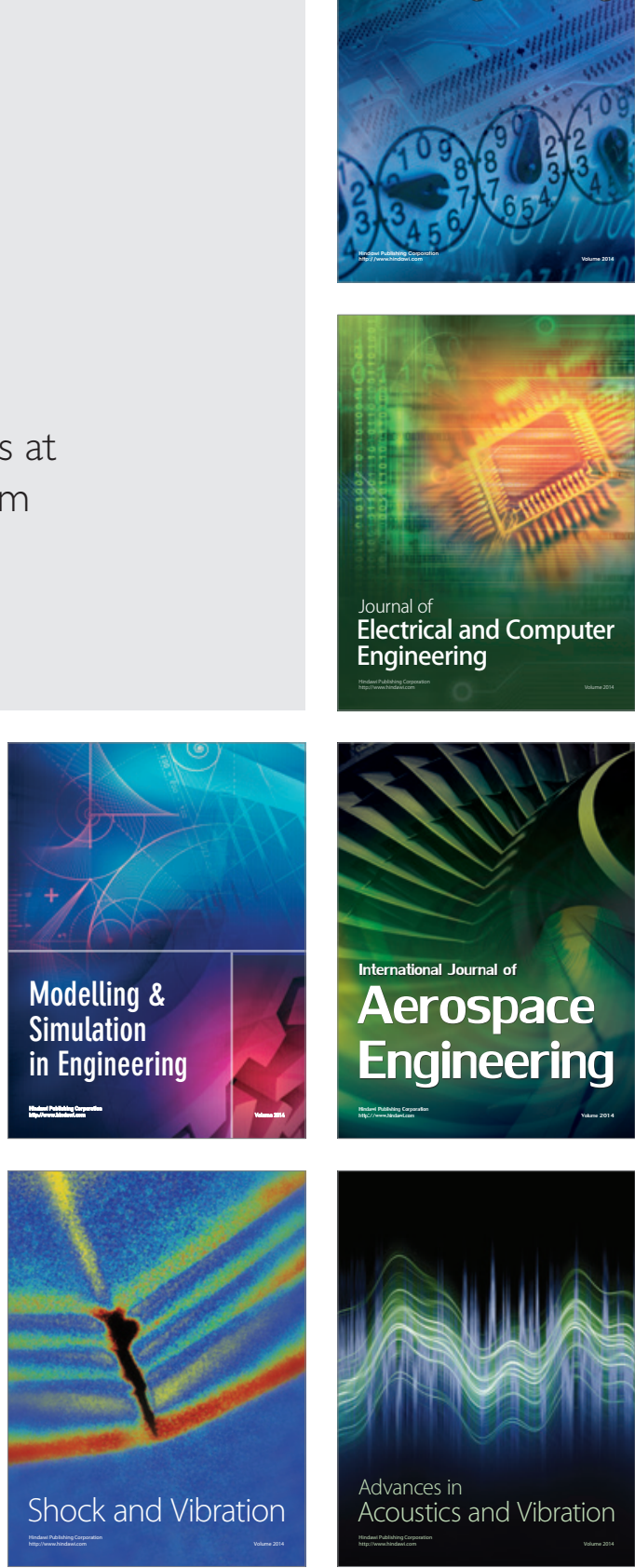